\title{
Deleterious RAD50 Gene Mutation
}

National Cancer Institute

\section{Source}

National Cancer Institute. Deleterious RAD50 Gene Mutation. NCI Thesaurus. Code

C150158.

A change in the nucleotide sequence of the RAD50 gene that is associated with increased risk of disease. 